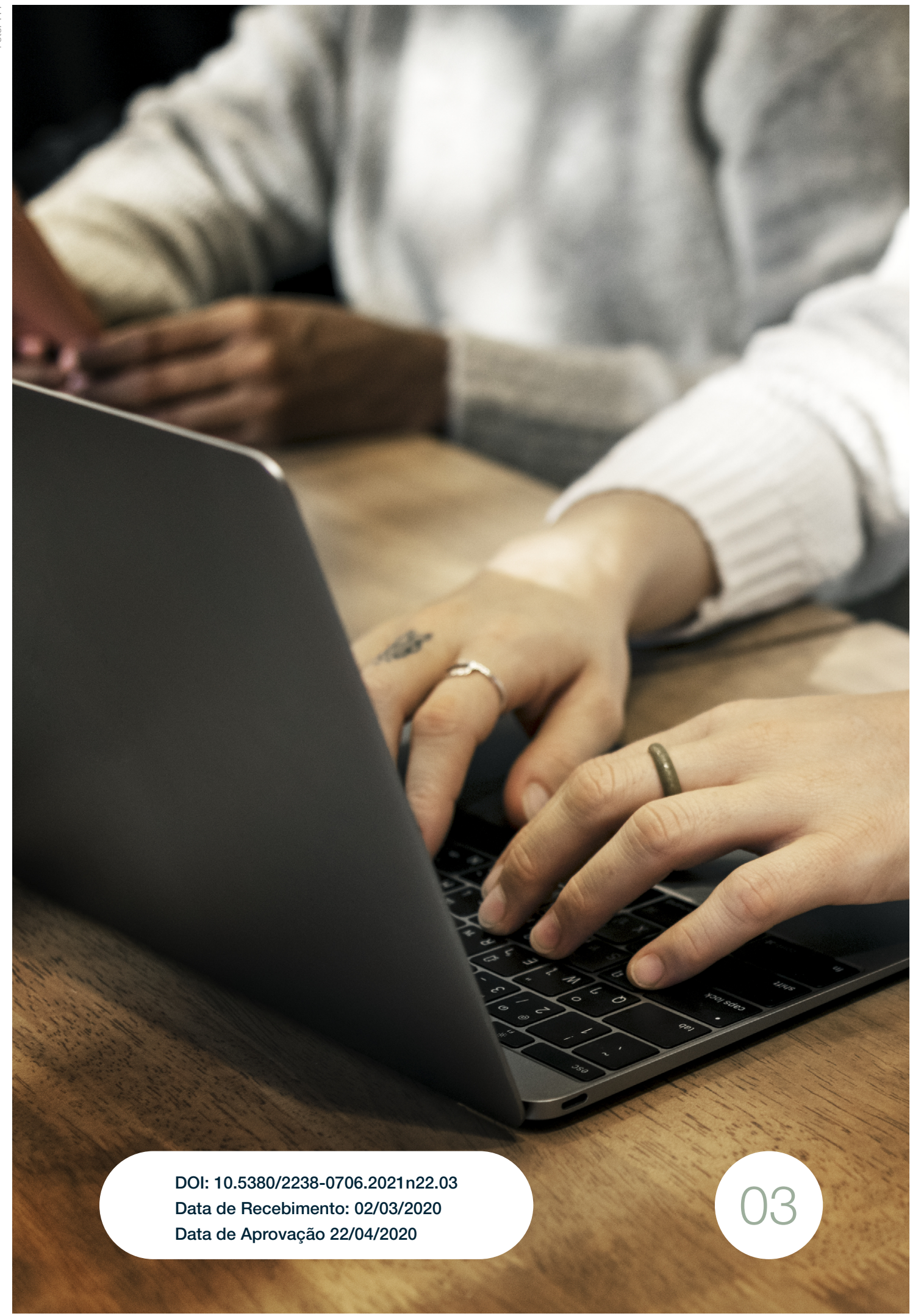


Contribuição, limites e possibilidades latinoamericanas para as ciências da comunicação 


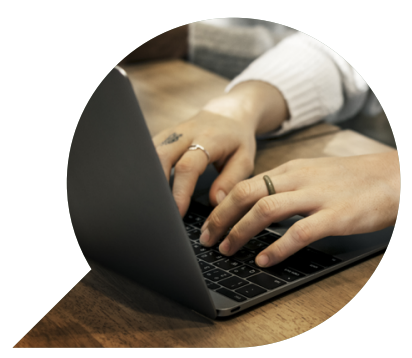

\section{Contribuição, limites e possibilidades latino-americanas para as ciências da comunicação}

Contribution, limits, and possibilities from Latin America for communication sciences

Contribución, límites y posibilidades latinoamericanas para las ciencias de la comunicación

BRUNO SANTOS NASCIMENTO DIAS ${ }^{1}$

Resumo: Este artigo propõe uma revisão histórica e conceitual do pensamento crítico sobre comunicação na América Latina para, a partir disto, identificar quais as suas contribuições, limites e possibilidades. Partindo da perspectiva contemporânea da crítica decolonial, que situa a comunicação no contexto das ciências modernas, observamos as origens do campo comunicacional na região, com seus modelos, referentes fundacionais e processos de institucionalização até chegar ao momento presente. Atualmente, esta linha de pensamento encontra-se entre um passado político e socialmente comprometido e um presente fragmentado e diversificado que oferece desafios e possibilidades dentre as quais se destaca a comunicação decolonial.

Palavras-chave: comunicação; América Latina; Decolonialidade.

1 Estudante do Doutorado em Ciências da Comunicação da Universidade de Coimbra - Portugal. 


\begin{abstract}
This article proposes a historical and conceptual review of critical thinking about Communication in Latin America to identify their contributions, limits, and possibilities. From the contemporary perspective of the decolonial criticism that places the Communication in the modern scientific context, we look at the origins of the communicational field in the region with its foundational models and referents, institutionalization processes until it reaches the present moment where it finds itself between a political past and socially compromised and a fragmented and diverse present that offers challenges and possibilities among which decolonial communication stands out.
\end{abstract}

Keywords: Communication; Latin America; Decoloniality.

Resumen: Este artículo propone una revisión histórica y conceptual del pensamiento crítico sobre la comunicación en América Latina para identificar sus contribuciones, límites y posibilidades. Partiendo de la perspectiva contemporánea de la crítica decolonial, que sitúa la comunicación en el contexto de las ciencias modernas, observamos los orígenes del campo comunicacional en la región, con sus modelos, referencias fundamentales y procesos de institucionalización hasta el momento presente. Actualmente, esta línea de pensamiento se encuentra entre un pasado comprometido política y socialmente y un presente fragmentado y diversificado que ofrece desafíos y posibilidades, en la que se destaca la comunicación decolonial.

Palabras clave: Comunicación; Latinoamérica; Decolonialidad.

\title{
Introdução
}

O presente artigo propõe analisar o percurso e lugar dos estudos de comunicação na América Latina para então refletir sobre suas contribuições, limites e possibilidades para o campo comunicacional. Para isso, recorremos a autores e leituras basilares dos estudos de comunicação latino-americanos, bem como a pesquisadores que têm se debruçado sobre a trajetória de teorias e pesquisas produzidas ao longo 
das últimas décadas na região e que ajudam a identificar os encontros, tensões e desafios que conformam a história das Ciências da comunicação na América Latina.

Cabe destacar a existência de uma variedade de cuidadosos trabaIhos de historização, compilação, metapesquisa e memória da pesquisa em comunicação realizados a partir de e para a América Latina, seja nas dimensões nacionais, regionais ou mesmo vertentes e subcampos. O que o presente artigo propõe é contribuir para estes esforços, associando-os aos debates contemporâneos que, sob o guarda-chuva dos estudos pós-coloniais, apresentam uma crítica à ocidentalização predominante no campo acadêmico e às logicas de organização transnacional do conhecimento. Estes elementos contribuem na medida em que lançam luz sobre as relações de poder na construção de uma história internacional da comunicação.

Através da revisão bibliográfica, iniciamos com a compreensão do lugar da comunicação enquanto ciência, problematizando seu caráter ocidentalizado vinculado à concepção moderna de conhecimento e, nesse contexto, suas perspectivas dominantes. Logo, voltamos o olhar para a América Latina, a trajetória de conformação do campo na região e o debate sobre a existência de um pensamento de marca latino-americana em comunicação. Finalmente, analisamos as contribuições e limites do pensamento sobre o fenômeno comunicacional neste continente, além dos desafios e possibilidades contemporâneos, no qual destacamos a proposta de uma perspectiva a partir da crítica decolonial.

\section{Comunicação, ciência e modernidade}

Nossa reflexão parte da perspectiva da crítica decolonial, que propõe um lugar geográfico e epistemológico para olhar a questão apresentada. Tal perspectiva é orientada pelas proposições da rede Modernidade/ Colonialidade ${ }^{2}$ que desde o fim do século passado tem posto em questão, a partir da América Latina, a ideia de que com o fim dos sistemas

2 Segundo Luciana Ballestrin (2013) o grupo Modernidade/Colonialidade se constitui a partir do final dos anos 1990 através de seminários, reuniões e publicações de intelectuais e pesquisadores em distintas áreas do conhecimento, de diversos países da América Latina e vinculado a diferentes Universidades no continente e nos Estados Unidos. As reflexões postas em marcha pelo grupo permitiram a renovação crítica do pensamento socia latino-americano por meio da contextualização e radicalização para o continente das formulações pós-coloniais. 
coloniais e a instituição dos estados-nação, estas regiões comportariam na atualidade sociedades descolonizadas. Pelo contrário, este processo não transformou substancialmente a estrutura das relações centro-periferia em escala mundial (CASTRO-GÓMEZ; GROSFOGUEL, 2007), colocando em questão a noção de modernidade como momento histórico de progresso humano que tem a Europa como referente civilizatório. Na esfera do conhecimento, o projeto moderno estabelece o "pensamento abissal" (SANTOS, 2009), um sistema de distinções que divide a realidade social (natureza/cultura, sujeito/objeto, humano/ não-humano) e atribui à ciência o monopólio do conhecimento, desqualificando formas não-científicas de verdade. A concepção moderna de ciência também fundamenta a crença de que é possível observar a realidade a partir de um lugar neutro e absoluto que habilitaria o observador a alcançar verdades universais (CASTRO-GÓMEZ, 2007).

A crítica decolonial, ao decodificar os padrões de poder modernos, propõe uma outra maneira de conceber o conhecimento e o fazer científico. Afinal, "se o conhecimento é um instrumento imperial de colonização, uma das tarefas urgentes que temos adiante é descolonizar o conhecimento" (MIGNOLO, 2010, p. 11). ${ }^{3}$ Assim, pensar a contribuição da América Latina para as ciências da comunicação a partir de uma perspectiva decolonial, tomando em conta a história e atualidade da região, é uma tarefa não apenas pertinente como necessária.

\section{Comunicação: uma história moderna}

Ao olhar para as ciências da comunicação observamos que, como os demais campos do conhecimento, ela se orienta pela concepção que demarca o norte colonizador como lugar do pensamento e produção da razão e o sul colonizado como espaço de "experimentação" e objeto do conhecimento (CONNELL, 2012). É possível notar, tanto em textos de divulgação científica como em programas universitários ao redor do mundo, que na produção do pensamento comunicacional prevalece um pequeno grupo de pensadores ocidentais com noções elaboradas prioritariamente a partir dos Estados Unidos ou Europa. É comum,

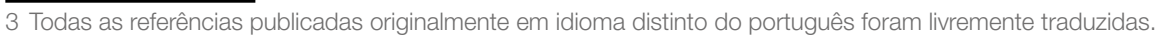


também, a predominância de uma perspectiva empírica, mensurável e aplicável, vinculada a interesses políticos e econômicos, além de convencional considerar sua "origem" pela identificação de Kurt Lewin, Carl Hovland, Harold Lasswell e Paul Lazarsfeld como seus "pais fundadores" (TORRICO VILLANUEVA, 2015). Desde sua conformação como campo de conhecimento a comunicação adotou argumentos orientados pela objetividade e utilidade instrumental do saber, estruturando seu perfil de cientificidade por meio de um arcabouço constituído, sobretudo, por uma epistemologia desenvolvida no Norte e de caráter positivista, com metodologias empírico-quantitativas e orientada pelo funcionalismo:

O lugar (locus) inicial de enunciação do saber comunicacional esteve marcado concretamente tanto por uma colocação geográfica, uma situação histórica, uma concepção epistemológica, uma noção de ciência, um critério metodológico e um dispositivo linguístico-cultural, como por interesses e finalidades histórico-sociais orientados pelo desenho civilizatório eurocêntrico (TORRICO VILLANUEVA, 2015, p. 47).

David Hesmondhalgh e Jason Toynbee (2008) apresentam um panorama interessante que ajuda a compreender o percurso histórico da comunicação enquanto campo de estudo. Eles destacam a distinção necessária entre teorias da comunicação e teoria da mídia, assumindo que a maneira mais comum de dividir este último é de acordo com o triângulo clássico: produção, textos e audiências; enquanto a teoria da comunicação é compreendida a partir de uma tendência mais histórica, normalmente descrevendo seu desenvolvimento inicial nos Estados Unidos, com a "pesquisa administrativa" de um lado e a Teoria Crítica de Adorno e outros membros da Escola de Frankfurt do outro, seguido pelo Estudos dos Efeitos, entre os anos 1950 e 1960 e logo pela pesquisa crítica influenciada pela teoria cultural, surgida nas décadas de 1970 e 1980. Hesmondhalgh e Toynbee (2008) observam nos estudos de comunicação um "midiacentrismo" e "paroquialismo" que é percebido na trajetória do debate sobre "economia política" x "estudos culturais" da seguinte maneira: 
Quadro 1 - Características dos campos e estudos da comunicação.

\begin{tabular}{|c|c|c|}
\hline & Economia Política & Estudos Culturais \\
\hline Origem & \multicolumn{2}{|c|}{ Origem no marxismo } \\
\hline $\begin{array}{c}\text { Contralidade } \\
\text { de mídia }\end{array}$ & $\begin{array}{c}\text { Mercadorias culturais e papel } \\
\text { da mídia no capitalismo }\end{array}$ & $\begin{array}{c}\text { Questões interligadas de } \\
\text { ideologia e representação }\end{array}$ \\
\hline Foco & Produção & Supraestrutura \\
\hline Exame & Notícias e mídia factual & $\begin{array}{c}\text { Cultura pupblico e consumo e mídia de } \\
\text { entretenimento }\end{array}$ \\
\hline Reivindicação & Formulação política da mídia & $\begin{array}{c}\text { Experiência cotidiana da } \\
\text { mídia }\end{array}$ \\
\hline $\begin{array}{c}\text { Fundamento } \\
\text { político pós } \\
1989\end{array}$ & $\begin{array}{c}\text { A propriedade pública e } \\
\text { do controle da mídia no } \\
\text { interesse da racionalidade } \\
\text { comunicativa }\end{array}$ & $\begin{array}{c}\text { A representação de } \\
\text { identidades específicas de } \\
\text { grupos na mídia e através } \\
\text { dela }\end{array}$ \\
\hline Ênfase & $\begin{array}{c}\text { Entender a economia e a } \\
\text { política como fatores causais } \\
\text { primários na formação do } \\
\text { caráter da mídia. }\end{array}$ & $\begin{array}{c}\text { Importância da cultura } \\
\text { e a natureza autônoma } \\
\text { e construída de todo } \\
\text { conhecimento. }\end{array}$ \\
\hline
\end{tabular}

Fonte: Elaboração própria.

Enquanto o "paroquialismo teórico" seria o processo de os estudos de mídia voltarem-se cada vez mais para si mesmo, à medida que a mídia e a cultura se tornaram tópicos importantes nas ciências sociais, o "midiacentrismo" se explica na observação de que:

os dois campos de estudos da mídia se tornaram mais centrados na mídia, mais preocupados em justificar quais elementos ou processos da mídia eram fundamentais, enquanto a questão maior da mídia na sociedade, com a qual o debate começara, se tornou menos importante (HESMONDHALGH; TOYNBEE, 2008, p. 8).

Mesmo os autores considerando as limitações dessas divisões, principalmente por perceberem nela uma ausência de teoria social crítica, no caso da teoria da comunicação, e de questões filosóficas de normatividade e explicação, no caso da teoria da mídia, não questionam a "convencionalidade" da centralidade do pensamento 
euro-estadunidense na construção de uma história dos estudos de comunicação. O panorama apresentado é uma síntese razoável do entendimento predominante sobre os paradigmas que orientam as ciências da comunicação, no qual prevalece uma concepção de comunicação como processo mediado tecnologicamente, que gera efeitos e em que a ação unilateral do emissor tem prevalência sobre os receptores, mesmo que se reconheça nestes alguma capacidade de agência.

\section{Campo e institucionalização na América Latina}

A comunicação latino-americana é, historicamente, vinculada a teorias, conceitos e metodologias estabelecidos na Europa e Estados Unidos. Esta constatação estava presente já nos seus primeiros anos (BELTRÁN, 1974) e segue evidente no trabalho de muitos pesquisadores que continuam se dedicando a revisar a produção comunicacional da região. Tal relação, entretanto, não impediu que se alcançasse uma certa autonomia com características e formulações próprias e que eventualmente se distancia das concepções hegemônicas.

Uma dessas características é a de uma produção condicionada por circunstâncias políticas e sociais específicas. Erick Torrico Villanueva (2016b) aponta que a orientação à subversão é uma marca do pensamento latino-americano. Os escritos do cubano José Martí, do uruguaio José Enrique Rodó e dos peruanos Manuel González Prada e José Carlos Mariátegui, são exemplos de como já no final do século XIX e início do Século XX, a influência do modelo político, econômico e social americano, bem como o racismo, exploração e a condição desigual da região já inspiravam um pensamento crítico no continente. Cabe destacar também o projeto intelectual do filósofo Leopoldo Zea Aguilar, que empreendeu uma reflexão crítica sobre a história e as características do pensamento latino-americano pós-independência como forma de reivindicar uma identidade intelectual para a região. A articulação e organização de um movimento de História das Ideias na América Latina a partir dos anos 1940 tem Zea como seu fundador e principal líder (SANTOS, 2016).

$\mathrm{Na}$ comunicação, ainda que algumas escolas e trabalhos relacionados ao jornalismo e à literatura já existissem, é principalmente a partir 
dos anos 1960 que o pensamento sobre comunicação começa a ganhar corpo no continente, muito em resposta às necessidades e demandas sócio-políticas vividas na região. Tem, por isso, forte orientação da crítica marxista, vinculado principalmente à Escola de Frankfurt e um assumido sentido de compromisso com a transformação social, sendo alguns de seus primeiros pensadores, além de pesquisadores, ativistas que militavam junto a movimentos sociais (TORRICO VILLANUEVA, 2016a). Esta característica, que se manteve em certa medida na década seguinte, é a que permite afirmar que "o movimento comunicacional mais intenso dos anos de 1960 e 1970 tenha ocorrido principalmente fora das faculdades" (FUENTES NAVARRO, 2019, p. 36, grifo do autor). O pensamento sobre comunicação que começa a ganhar corpo na segunda metade do século XX é, em síntese:

um pensamento reflexo, espelhando as matrizes das ideias comunicacionais hegemônicas na Europa Ocidental e na América do Norte. Mas ele vai assumindo identidade própria, na esteira do movimento intelectual inspirado em duas matrizes ideológicas convergentes: a teoria da dependência e a Teologia da Libertação (DE MELO; GOBBI; DOS SANTOS, 2001, p. 9).

Para Luís Ramiro Beltrán (2007, p. 5), foi na década de 1960 que se publicaram os primeiros estudos que fundamentavam a corrente de pesquisa que nos anos seguintes passaria a ser conhecida como a "Escola Latino-americana de comunicação": Comunicación y Cultura de masas de Antonio Pasquali, em 1963, e Conducta, estructura y comunicación de Eliseo Verón, em 1968. Ao final desse decênio, predominou na região a ideia de que os meios de comunicação de massa eram agentes de mudança, capazes de conduzir os países subdesenvolvidos do seu tradicionalismo atrasado à prosperidade moderna. O que seria questionado já nos anos subsequentes.

É convencional a compreensão da década de 1960 como o marco inicial de um pensamento latino-americano sobre comunicação de caráter político. No entanto, uma variedade de autores lança mão de diferentes enfoques e distintas possibilidades de temporizações históricas para compreender esse percurso. Raúl Fuentes Navarro (2019), por exemplo, considera o período de 1939 a 1967 como aquele no qual "as perspectivas funcionalistas e desenvo/vimentistas de comunicação de massa confrontaram-se com as críticas e militantes derivadas do modelo 
socialista inspirado na Revolução Cubana" (FUENTES NAVARRO, 2019, p. 40, grifo do autor), e destaca ainda nesse período a fundação, em 1959, do Centro Internacional de Estudios Superiores de Comunicación para América Latina (CIESPAL) em Quito, no Equador.

O período seguinte, de 1968 a 1988, foi o de consolidação da pesquisa acadêmica da comunicação e de intensos processos sociopolíticos em vários países latino-americanos, como golpes de Estado e retornos à democracia, guerras civis e repressão de movimentos insurgentes e a criação de blocos regionais. Estes contextos sociais estimularam estudos críticos sobre fluxos de informação, desigualdade e dependência dos países latino-americanos, além de proposta de políticas de comunicação nacionais; foram criados os primeiros programas de pós-graduação e publicados livros considerados fundacionais para a consolidação de um pensamento comunicacional crítico latino-americano, como Pedagogia do oprimido e Extensão ou comunicação, de Paulo Freire; Cuadernos da Realidad Nacional por Armand Mattelart no Chile, e De los medios a las mediaciones de Jesús Martín-Barbero. O último período na leitura de Fuentes Navarro, que inicia em 1989 e segue até os dias atuais, é o de um paradoxo: ao passo que se consolidam os estudos de comunicação na região, diminuem os esforços de colaboração para produzir uma teoria propriamente latino-americana.

Por sua vez, Erick Torrico Villanueva (2016a), em sua análise sobre o pensamento comunicacional latino-americano no período entre 1960 e 2009, propõe um enfoque na produção teórico-conceitual e seu entorno a partir de uma periodização por décadas. O primeiro período, até 1969, é o da "crítica e articulação temática", com produção inovadora, inspirada no pensamento crítico e que propunha uma compreensão da comunicação nos seus âmbitos humano e social, para além do descritivo. O período de 1970 a 1979 é identificado como o de "compromisso utópico" e se caracterizou pela realização dos primeiros encontros acadêmicos e fortalecimento institucional em nível regional. Além disso, "a denúncia da ideologização mass-midiática e do domínio informativo transnacional prevaleceram neste período junto à formulação de alternativas para a mudança do sistema de comunicações" (TORRICO VILLANUEVA, 2016a, p. 152, grifo do autor). Entre 1980 e 1989, durante os anos de "legitimação do campo", houve grande produção de conceitos sobre comunicação na América Latina, multiplicação de cursos 
universitários e uma emergente preocupação pela delimitação de um campo de estudos de reconhecimento acadêmico. Na década seguinte se deu a "Institucionalização da comunidade" com a refundação da ALAIC, em 1988, e a perda de protagonismo dos organismos internacionais e centros de pesquisa para as universidades como espaço de pesquisa e debate. No âmbito da produção científica, "as questões tanto da produção de significados como dos códigos e mediações, relacionadas em geral com a vertente cultural, tiveram uma forte presença no trabalho de ideação registrado nesta década" (Ibid, p. 226).

Finalmente, entre 2000 e 2009, período de "consolidação orgânica", o autor destaca um notável crescimento da produção bibliográfica, e a continuidade da realização periódica dos congressos e seminários da ALAIC, proporcionando um diálogo mais intenso entre a produção científica sobre comunicação na América Latina e outras regiões do mundo. Torrico Villanueva identifica, ainda nesta década, o predomínio do caráter "renovador" das teorias e conceitos utilizados, o que pode significar, de alguma maneira, um reavivamento da abordagem crítica, mesmo que com tendências despolitizadas e vinculadas a "preocupações de ordem cultural como a produção simbólica e de sentidos” (Ibid, p. 202).

Vale destacar ainda o enfoque e periodização descrita por Gustavo León-Duarte em 2009 com base na proposta de José Marques de Melo. Nesta perspectiva, a década de 1960 se destaca pelo trabalho de alguns estudiosos representantes do período embrionário no estudo da comunicação na América Latina e que "lançaram as 'teses originais' e 'construções científicas autóctones' no estudo dos fenômenos comunicacionais" (LEÓN DUARTE, 2009, p. 134). Na década seguinte tem-se o surgimento dos "inovadores", que foram os responsáveis pelo avanço metodológico dos estudos comunicacionais que incorpora modelos analíticos provados nas ciências da linguagem e nas Ciências Sociais em geral. Nos anos 1980 temos os "renovadores", grupo forte de intelectuais que, vinculados a faculdades de comunicação de diversas universidades da região, teve a capacidade de compreensão e explicação do pensamento latino-americano sobre meios de comunicação, estruturas de poder, mediações culturais, usos e gratificações sociais, potencialidades educacionais etc. A geração seguinte, dos anos 1990, é a dos "continuadores", que abandonaram o perfil "extranacional" para assumir uma identidade "multifacética" em torno a uma região estruturada por "comunidades nacionais" de pensadores da comunicação. 
É possível perceber como os que pensaram a comunicação na América Latina ao longo dos últimos 60 anos foram férteis em sua produção e comprometidos com a reflexão engajada e responsável sobre o fenômeno comunicacional. Este processo segue em curso e resta ainda a oportunidade de análises mais detalhadas e sistemáticas para os períodos mais recentes, onde se destaca uma presença cada vez mais intensa de grupos antes excluídos e invisibilizados com seus saberes e formas de conhecimento nos espaços acadêmicos, a intensificação das tecnologias de comunicação, controle e gestão automatizada de informação por grupos econômicos transnacionais e demandas políticas, econômicas e climáticas que apresentam novas e complexas realidades.

\section{Uma vertente latino-americana?}

Um momento importante para uma reflexão a respeito do pensamento comunicacional na América Latina ocorreu no I Seminário Latino-americano sobre a Investigação da Comunicação, na cidade boliviana de Cochabamba em novembro de 1999. Nesta ocasião, o professor José Marques de Melo apresentou um trabalho no qual reivindicava a existência do que chamou de "Escola Latino-Americana de Comunicação" (ELACOM). De acordo com o relato de um dos coordenadores do evento Erick Torrico Villanueva (2000), Marques de Melo propôs uma revisão de fases e autores que compõem o que considerava esta Escola, argumentando que ela seria caracterizada por "sua miscigenação teórica, seu hibridismo metodológico, seu compromisso ético-político e sua dimensão extranacional" (TORRICO VILLANUEVA, 2000, p. 9). A proposta, entretanto, foi prontamente questionada por Guillermo Orozco, para quem falar em uma "Escola" implicaria certas homogeneidades que a comunicologia latino-americana carecia. Concordou, porém, com alternativas também propostas por Marques de Melo, como a de uma "vertente latino-americana em comunicação". A ELACOM levada a cabo pelo professor Marques de Melo terminou demasiadamente dependente de sua figura e, apesar de ter resultado em um colóquio realizado anualmente entre 1997 e 2016, foi bastante questionada: 
se é inegável que existe um pensamento comunicacional com selo latino-americano que se manifesta no cenário da comunidade acadêmica regional e se projeta de vez em quando no internacional, o fato de que se tivesse chegado a formar una escola própria neste campo é bastante discutível (TORRICO VILLANUEVA, 2016a, p. 99).

Apesar de comum a crítica à ideia da existência de uma escola latino-americana de comunicação sob argumento de que a pesquisa regional neste campo é bastante heterogênea, é corrente também o entendimento de que essa fragmentação não se traduz em ausência de cooperação e intercâmbio. De fato, a fragmentação é um dos obstáculos que enfrenta a comunicação em nível internacional na reivindicação de um status disciplinário. É também central na discussão sobre a dispersão temática e teórico-metodológica do campo. Na América Latina, entretanto, tem coexistido paradoxalmente com uma crescente concentração da produção e distribuição de contribuições científicas (FUENTES NAVARRO, 2016).

Em texto publicado em 2014, Silvio Waisbord argumenta que, diferente do que se observou nos Estados Unidos e em parte da Europa, o pensamento em comunicação na América Latina tem raízes teóricas e analíticas comuns, estabelecidas nas décadas de 1960 e 1970, de tal maneira que, nessa região, "o campo de estudos de comunicação/mídia permanece unido, ainda que fragmentado" (WAISBORD, 2014, p. 56). Aponta que, principalmente no que diz respeito ao estudo do imperialismo na mídia e na cultura, das inovações nas políticas de comunicação e da interseção entre mídia e dinâmica cultural, o pensamento latino-americano produziu fundamentos que se consolidaram e expandiram através de uma variedade de pesquisas, universidades e linhas de investigação.

Para Torrico Villanueva (2016a) é este fundamento teórico e analítico comum que caracteriza a comunicação em via latino-americana que é, ademais, de caráter "crítico e inovador", orientado à subversão e contestação. Com um pensamento que emerge a partir dos anos 1960, a América Latina configura um "locus multideterminado", isto é, situado geográfica e historicamente, pois é conformado territorialmente por ex-colônias ibéricas que compartilham uma condição inferiorizada na história mundial e de onde se pode compreender a realidade de uma perspectiva diferente da euro-estadunidense hegemônica. Para este autor, o pensamento latino-americano sobre o fenômeno comunicacional foi capaz de produzir uma episteme própria: 
regida por um código crítico surgido da subalter(n)idade e que é o ordenador das percepções, interpretações e discursos, ao passo que dá lugar a um horizonte de apreensão intelectual questionador que orienta o que se considera possível e necessário ver, dizer e fazer no campo de estudos da comunicação (TORRICO VILLANUEVA, 2016b, p. 34).

Existiria, assim, um modo regionalizado de compreender os processos comunicacionais que se nutre da densidade histórica do continente e implica a priorização da análise crítica que permite outras formas de realidade e a certeza de que a teorização deve necessariamente promover emancipação.

É, portanto, factível pensar em uma vertente, tradição ou marca latino-americana para a pesquisa em comunicação que, como toda categorização nesses termos, não é nem deve pretender ser determinante, mas busca, a partir do estabelecido, sugerir caminhos para atender demandas locais, mas de projeção transregional, questionar os modelos hegemônicos e promover a diversidade de saberes, perspectivas e formas de conhecimento.

\section{América Latina: das contribuições e limites às possibilidades}

A base da reflexão e o "cânone" comum do pensamento crítico latino-americano em comunicação, portanto, é fruto de um processo histórico específico, de transformações sociais, implicações políticas e da necessidade de desconstrução de aparatos teóricos externos, mas também da solidariedade e interconexão entre pesquisadores e instituições em nível continental. Trata-se de uma trajetória de forte apelo identitário e emancipador. Em uma possível síntese, Omar Rincón afirma que:

Na América Latina, a comunicação sempre foi outra coisa: um assunto não somente de meios ou tecnologias, mas de processos, práticas e experiências de cultura; mais do que jornalismo ou meios de comunicação. Em tempos de ditaduras e autoritarismos, a comunicação recorreu às heranças da sociologia, da política, da literatura, da arte, da antropologia; também, do diverso, do inquieto, do dissidente, do popular; porém, sobretudo quando era quase impossível ser livre na América Latina, a comunicação foi imaginada a partir de baixo, com as pessoas e pela libertação (RINCÓN, 2018, p. 66-67, grifo do autor). 
Esta narrativa, mesmo não sendo unânime, é o pano de fundo para um grupo significativo dentre aqueles que contam a história do pensamento latino-americano em comunicação e, além da sua maior contribuição é "a base da originalidade alcançada pela região no plano do conhecimento dos fenômenos comunicacionais" (TORRICO VILLANUEVA, 2016b, p. 34). Um olhar atento à produção contemporânea permite perceber que tais características seguem presentes, ${ }^{4}$ mas não é isenta de limites e críticas, muitas das quais identificadas pelos mesmos que ajudaram e ajudam a construir sua história.

Uma destas encontra-se na percepção de que o compromisso político dos modelos teóricos fundacionais e que atribuíram a marca latino-americana, terminaram incorporados pela história dos processos de lutas da região, promovendo uma natural libertação das influências dominantes que os fundamentaram e uma intertextualidade teórica própria, na qual muitos conceitos e teorias foram sendo revisados, reelaborados e até descartados (FUENTES NAVARRO, 2019). Além disso, a exaltação do fato de que o pensamento crítico latino-americano é fundamentado em uma "raiz comum", acompanha a observação de que isto não impediu sua fragmentação e que, embora "tenha produzido ricos estudos empíricos sobre inúmeras questões, não necessariamente contribuiu para a produção de argumentos inovadores, ambiciosos e influentes que alguma vez foram distintivos da tradição 'latino-americana'” (WAISBORD, 2014, p. 56).

É importante ressaltar também que o número crescente de universidades, cursos e espaços destinados à pesquisa em comunicação na região, não deve estar condicionado pelo histórico que o promoveu. Isto é, aquilo que se considera a marca do pensamento comunicacional latino-americano não deve determinar os limites do que será entendido como esse pensamento no futuro. Primeiramente porque uma pesquisa latino-americana em comunicação não deve ser entendida como o mesmo que uma pesquisa em comunicação produzida na América Latina. Também porque toda pesquisa em comunicação latino-americana tem a possibilidade de seguir sendo latino-americana mesmo não assumindo os mesmos compromissos que caracterizaram os trabalhos do passado. A isso soma-se a já comentada geopolítica do

4 Para mais algumas reflexões e estudos concretos recentes, cf. Caballero e Maldonado (2016), Bonin, Loriete Garcia e Maldonado (2016), Jacks et al (2017), Druetta (2018) e Kaplun (2019). 
conhecimento e as relações de poder por elas estabelecidas. Sem romper as hierarquias que privilegiam Europa e Estados Unidos como centro do conhecimento sobre a comunicação, esta "ordem internacional", em geral, apenas aceita e permite o pensamento produzido na América Latina enquanto vinculado à tradição latino-americana. Para além disso, qualquer tentativa de transcender as fronteiras regionais tem de enfrentar uma série de fatores estruturais relacionados, como a prevalência imposta do inglês como idioma "universal" e o acesso desigual a recursos e espaços de circulação do conhecimento, financiamentos, congressos, literatura, editoras etc. (TORRICO VILLANUEVA, 2015; FUENTES NAVARRO, 2019).

Neste horizonte difuso e complexo faz-se necessário identificar também os caminhos que uma pesquisa em comunicação que se reivindique latino-americana pode seguir. Na percepção de parte significativa dos autores consultados, um pensamento sobre a comunicação de marca latino-americana é, necessariamente, um pensamento imbuído do seu passado. Não como tributário ou dependente, mas sim como originário de um sentido de realidade que é compartilhado em variadas dimensões. A proposta de Fuentes Navarro para uma construção da memória e historização da pesquisa em comunicação na América Latina é referente para compreender o cenário atual e futuro: "o foco nas tensões e antagonismos" pode ser muito mais esclarecedor que "a imaginação de fluxos unidirecionais de influência ou recursos, ou a defesa de excepcionalismos históricos, nacionais ou regionais" (FUENTES NAVARRO, 2019, p. 38, grifo do autor). Sob a perspectiva de um discurso científico que é inerente à uma revisão contínua das premissas, métodos e propostas na articulação com distintas práticas, contextos e estruturas sociais que se assumem como objeto, a pesquisa em comunicação na região "deve aproveitar e cultivar o desejo permanente que caracteriza o campo dos estudos da comunicação de questionar a si mesmo, de analisar e discutir suas fundações e fundamentos" (lbid). Waisbord, por sua vez, argumenta com relação à necessidade de se adotar uma posição analítica semelhante a que promoveu a inovação teórica da comunicação latino-americana no passado: "uma visão cosmopolita que coloca as questões teóricas no centro da análise, aborda cautelosa e criticamente as teorias produzidas em diferentes contextos, e participa de debates na comunidade global de estudiosos de comunicação e mídia" (WAISBORD, 2014, p. 56). Um caminho 
similar ao pensado por Omar Rincón, para quem, assim como "os que vieram antes construíram outros modos de fazer, pensar, criar e investigar a comunicação a partir da América Latina" (RINCÓN, 2018, p. 75) cabe aos de agora, fazer "de outro modo", reinventando politicamente os discursos sobre a comunicação, lançando mão de "táticas mágicas" presentes na diversidade das formas de ser e conhecer de povos originários da região, na experiência de luta de grupos de jovens, negros e mulheres e com as pessoas nos territórios, para imaginar maneiras outras de estar no mundo:

proponho que devemos nos assumir como culturas bastardas, filhos do pop e do popular, do folk e do culto, do populista e do subalterno, da arte e do típico, ou seja, que nossa comunicação é atravessada por muitos pais (...) a única possibilidade que nos resta como bastardos é assumir essa característica como lugar de enunciação, e a Mãe Terra, o território e a identidade de alguém como o lugar legítimo a partir do qual se enuncia, se cria, se investiga e se subverte (RINCÓN, 2018, p. 77, grifo do autor).

É nesse sentido que retomamos a concepção e perspectiva propostos pela crítica decolonial, que exploramos ao início desse texto, pois é ela quem, atualmente e a partir da América Latina, oferece referentes, conceitos e categorias para o desmonte das estruturas de análise e crítica que prevalecem no campo comunicacional. Trata-se de um horizonte de compreensão que remete aos fundamentos do pensamento crítico latino-americano sobre a comunicação, mas transcende o debate centrado no poder, processo ou impacto da mídia proveniente dos modelos convencionais:

A reflexão e proposta decoloniais que aqui se apresenta operam em nível duplo: no epistemológico, onde advoga por historizar e recompor as bases do conhecimento a partir da sub/alternidade; e no teórico, em que se busca reconceitualizar a comunicação e sua área de estudo (TORRICO VILLANUEVA, 2018, p. 79).

A crítica decolonial não tem o interesse simples de contrastar modelos e teorias, mas, antes, de pôr em questão a concepção moderna de conhecimento, sua pretensa universalidade e sua violência no silenciamento e invisibilização de outras formas de saber. Para a comunicação isso implica uma mudança no ponto a partir do qual se entende 
seu fenômeno, já não mais no papel e poder das tecnologias que mediam o processo, mas "na sua natureza histórico-cultural e seu caráter constitutivo do humano e do social” (Ibid, p. 79). É uma radical mudança ontológica e epistemológica ainda em construção. Contudo, investigadores por toda a América Latina tem apresentado uma diversidade consistente de publicações com propostas teórico-conceituais para a comunicação a partir de uma crítica des/decolonial ${ }^{5}$.

No contexto da comunicação digital, que concentra grande parte da atenção dos pesquisadores contemporâneos, por exemplo, a perspectiva decolonial tem subsidiado a ação política feminista, queer e LGBTT que percebe as tecnologias digitais, com suas ferramentas e dispositivos, como cenários privilegiados. Em 2018, durante as sessões do Fórum Social Mundial realizado em Salvador-Brasil, um conjunto de organizações de diferentes regiões do Brasil debateu e aprovou o manifesto intitulado Princípios para a decolonização da internet, ${ }^{6}$ contemplando dezesseis pontos reivindicatórios que têm como eixo os princípios da cultura livre e da democratização das comunicações digitais. Iniciativas como estas têm como premissa o entendimento de que as práticas que os grupos subalternos realizam na utilização das tecnologias de informação se inserem num contexto tecno-comunicativo, político e econômico que busca manter as estruturas de dominação ancoradas na colonialidade do poder.

Além dos exemplos mencionados, vale ressaltar também que desde 2016, nos congressos da ALAIC, o Grupo de Interesse intitulado Comunicación - Decolonialidad vem compartilhando diversas experiências de trabalhos empíricos e teóricos a partir da perspectiva decolonial ${ }^{7}$.

\section{Conclusões}

A América Latina construiu ao longo dos últimos 60 anos uma história consistente e diversa para a comunicação. Olhar esse passado a

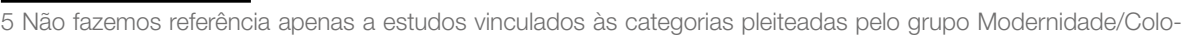
nialidade. Consideramos, sobretudo, trabalhos que apresentam propostas explícitas de combate à colonialidade principalmente (mas não apenas) na dimensão epistemológica. Contudo, não é o objetivo deste artigo aprofundar neste aspecto. Para algumas referências cf. Barranquero (2012), Baspinero (2016), Torrico Villanueva (2016c) e Sodré (2019).

6 Cf. https://www.academia.edu/40690857/Principios_para_a_descolonizacao_de_internet.

7 Cf. http://alaic2016.cua.uam.mx/memorias.phps e ‘http://alaic2018.ucr.ac.cr/es/memorias.
} 
partir do contexto atual é um desafio porque exige identificar intersecções e convergências que nos permitam perceber os caminhos percorridos, mas demanda o cuidado de não idealizar o passado a partir do presente. Este artigo se concentrou naquilo que pesquisadores que têm se dedicado a este exercício já há algum tempo apontam como o característico para a região, mas não é nem tem a pretensão de ser a única história possível. Muitas outras existem e devem ser contadas.

Os elementos nos quais nos concentramos, contudo, oferecem a base para o que a contemporaneidade demanda: a diversificação de vozes e formas de pensar, saber e conhecer. A comunicação na América Latina continua a produzir um considerável volume de estudos administrativos, aplicados e descritivos vinculados aos modelos tanto da tradição das teorias de mídia como da economia política e mesmo dos Estudos Culturais. Entretanto, uma parte significativa do que se tem produzido nas universidades tem sido orientada às vozes historicamente silenciadas no saber científico, como o de comunidades originárias, movimentos identitários e de setores populares. Na percepção da reflexão aqui proposta, essa é a contribuição mais significativa da região para as ciências da comunicação. A emergência e consolidação da crítica decolonial ao longo dos últimos vinte anos vem contribuir principalmente no sentido de oferecer categorias para analisar processos de emancipação de experiências, narrativas e práticas negadas nos modelos tradicionais e muitas vezes simplesmente instrumentalizadas na história do pensamento regional.

O que a história aqui contada aponta e a realidade contemporânea demanda é a necessidade de aproximação entre produção/reflexão acadêmica e as experiências cotidianas dos entornos estudados e dos sujeitos que as produzem. Isto implica que categorias e conceitos sejam também elaborados a partir de dentro, ou seja, priorizando as experiências e contribuições dos grupos investigados, em detrimento de formulações prévias e adaptadas. Não se trata de abandonar os procedimentos e rigor científico, mas de incluir, diversificar, multiplicar e a partir deles, produzir e reproduzir formas variadas de conhecer e compreender a comunicação, de dar espaço a epistemologias vinculadas às realidades locais com capacidade e potencial de dialogar em igualdade de condições com modelos já estabelecidos. 


\section{REFERÊNCIAS}

BARRANQUERO, Alejandro. Comunicación participativa y dominios del Vivir Bien. Una aproximación conceptual. Anais IV Congreso Internacional Latina de Comunicación Social. Universidad de La Laguna, La Laguna - Tenerife, 04 a 07 de dezembro de 2012. Disponível em: http://www.revistalatinacs.org/12SLCS/2012_actas.html. Acesso em: 10 dez 2020.

BASPINERO, Adalid C. Aruskipasipxañanakasakipunirakispaw. In: CABALLERO, Francisco Sierra; MALDONADO, Claudio (Orgs.). Comunicación, Decolonialidad y Buen Vivir. Quito: CIESPAL, 2016. p. 59-94

BELTRÁN, Luis Ramiro. Communication research in Latin America; the blindfolded inquiry? In: ANTEIL DER MASSENMEDIEN BEI DER HERAUSBILDUNG DES BEWUSSTSEINS IN DER SICH WANDELNDEN WELT 1974, Leipzig. Anais [...]. Leipzig: IAMCR, 1974.

La investigación de la comunicación, ayer y hoy. Temas y objetivos de investigación en la comunicación de ayer. Chasqui - Revista latinoamericana de comunicación, Quito, n. 100, p. 4-7, 2007.

BONIN, Jiani Adriana; LORITE GARCIA, Nicolás; MALDONADO, Alberto Efendy (Org.). Publicidad, propaganda y diversidades socioculturales. Quito: CIESPAL, 2016.

CABALLERO, Francisco Sierra; MALDONADO, Claudio (Orgs.). Comunicación, Decolonialidad y Buen Vivir. Quito: CIESPAL, 2016.

CASTRO-GÓMEZ, Santiago. Decolonizar la universidad. La hybris del punto cero y el diálogo de saberes. In: El giro decolonial. Reflexiones para una diversidad epistémica más allá del capitalismo global. Serie Encuentros, Bogotá: Siglo del Hombre, 2007. p. 79-91.

CASTRO-GÓMEZ, Santiago; GROSFOGUEL, Ramón. Prólogo. Giro decolonial, teoría crítica y pensamiento heterárquico. In: El giro decolonial. Reflexiones para una diversidad epistémica más allá del capitalismo global. Serie Encuentros, Bogotá: Siglo del Hombre, 2007. p. 9-23.

CONNELL, Raewyn. A iminente revolução na teoria social. Revista Brasileira de Ciências Sociais, São Paulo, v. 27, n. 80, p. 9-20, 2012.

DE MELO, José Marques; GOBBI, Maria Cristina; DOS SANTOS, Marli. Contribuições Brasileiras ao Pensamento Comunicacional Latino-Americano. Décio Pignatari, Muniz Sodré e Sérgio Capparelli. São Bernardo do Campo, São Paulo: UNESCO, p. 9-126, 2001.

DRUETTA, Delia Crovi (Org.). Sociedad del conocimiento y comunicación. Reflexiones críticas desde América Latina. São Paulo: ALAIC, 2018.

FUENTES NAVARRO, Raúl. Cuatro décadas de internacionalización académica en el campo de estudios de la comunicación en América Latina. Anuario electrónico de estudios en Comunicación Social "Disertaciones", Rosario, v. 9, n. 2, p. 8-26, 2016.

Pesquisa e metapesquisa sobre comunicação na América Latina. MATRIZes, São Paulo, v. 13, n. 1 , p. $27-48,2019$

HESMONDHALGH, David; TOYNBEE, Jason. Why media studies needs better social theory. In: The media and social theory. New York: Routledge, 2008. p. 15-38. 
JACKS, Nilda et al. Meios e audiências III: reconfigurações dos estudos de recepção e consumo midiático no Brasil. Porto Alegre: Sulina, 2017.

KAPLUN, Gabriel (Org.). ¿Vivir o sobrevivir? Sostenibilidad de las alternativas mediáticas en Uruguay. Montevideo: FESUR, 2019.

LEÓN DUARTE, Gustavo. Elacom: referente histórico e conquista da hegemonia no pensamento latino-americano da comunicação. Comunicação \& Sociedade, São Paulo, v. 28, n. 47, p. 115-158, 2009.

MIGNOLO, Walter D. Desobediencia epistémica: retórica de la modernidad, lógica de la coIonialidad y gramática de la descolonialidad. Buenos Aires: Ediciones del signo, 2010.

RINCÓN, Omar. Mutações bastardas da comunicação. MATRIZes, São Paulo, v. 12, n. 1, p. 65-78, 2018.

SANTOS, Boaventura de Sousa. Para além do pensamento abissal: das linhas globais a uma ecologia de saberes. In: SANTOS, Boaventura de Sousa; MENESES, Maria Paula (org.). Epistemilogias do Sul. Coimbra: Almedina, 2009. p. 23-72.

SANTOS, Luciano dos. A identidade da América Latina: o projeto intelectual de Leopoldo Zea. Goiânia: IFG, 2016

SODRÉ, Muniz. Pensar nagô. Petrópolis: Vozes, 2017.

TORRICO VILLANUEVA, Erick. Eventos: Cochabamba, sede de la más grande reunión académica sobre comunicación en Latinoamérica. Pensamiento Comunicacional Latinoamericano, Cochabamba, n. 2, p. 8-9, 2000.

. La "comunicación occidental". Eurocentrismo y Modernidad: marcas de las teorías predominantes en el campo. Journal de Comunicación Social, Cochabamba, v. 3, p. 41, 2015.

La contribución del pensamiento teórico latinoamericano a la constitución del campo conceptual de la comunicación: 1960-2009. Universidad Rey Juan Carlos, Madrid, 2016. Disponível em: https://dialnet.unirioja.es/servlet/tesis?codigo=171758. Acesso em: 9 dez. 2019.

. La comunicación en clave latinoamericana. Chasqui: Revista Latinoamericana de Comunicación, Quito, n. 132, p. 23-36, 2016.

. Hacia la Comunicación decolonial. Serie Integrar. Vol 2. Sucre: Universidad Andina Simón Bolívar, 2016.

La comunicación decolonial, perspectiva in/surgente. Revista Latinoamericana de Ciencias de la Comunicación, São Paulo, v. 15, n. 28, p. 72-81, 2018.

WAISBORD, Silvio. United and fragmented: Communication and media studies in Latin America. Journal of Latin American Communication Research, San Juan, v. 4, n. 1, p. 55-77, 2014.

Recebido em: 02/03/20

Aprovado em: 22/04/20 


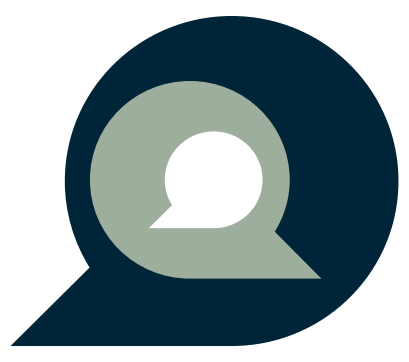

